\title{
Política, magia, semiótica : como resistir ao populismo autoritário e suas fantasias conspiratórias
}

\section{Paolo Demuru}

\section{Universidade Paulista}

\author{
A Lina \\ Unu mundu bellissimu pro tene \\ Como ch'est su filu ordidu \\ A bois toccat a tèssere, \\ Mizzi chi poi det essere \\ Tardu s'arrepentimentu; \\ Cando si tenet su bentu \\ Est prezisu bentular*
}

Francesco Ignazio Mannu Su patriotu sardu a sos feudatários

\section{Introdução}

Este texto está organizado em duas partes. Na primeira parte - pars destruens -, intitulada Desmontes, analiso um aspecto específico dos "populismos conspiratórios” de "ultradireita” do século XXI : a sua dimensão mágica e contagiante,

\footnotetext{
* Agora que a teia está urdida, / A vocês cabe tecer. / Pois tardio pode ser / o arrependimento. / Quando se tem o vento / É preciso debulhar.
} 
relativa aos encantos e êxtases que eles são capazes de proporcionar. Em seguida, ainda no âmbito de uma crítica desconstrutiva, questiono as falácias do assim chamado debunking, termo que define a confutação, por meio de dados objetivos e argumentos lógicos, das narrativas populista-conspiratórias : notícias falsas, crenças pseudocientíficas e/ou qualquer discurso não fundado em evidências devida e cientificamente comprovadas. Em outras palavras, procuro fazer um "desmonte" das mais comuns práticas de "desmonte" do populismo conspiratório. Defendo que uma crítica dos populismos conspiratórios do século XXI fundada apenas em amostras de dados e silogismos, além de soar esnobe e pedante, raramente convence alguém e mudar de opinião, por quão fora da realidade estas possam ser.

Na segunda parte, a pars construens, intitulada Recriar, busco algumas pistas que possam ser úteis para facejarmos o populismo de ultradireita e seus encantos conspiratórios. Alego que, enquanto estudiosos dos processos de produção de sentido, podemos e devemos contribuir a construir novas táticas para enfrentá-los. Ora, essas táticas não podem ser tão-somente da ordem do racional. Por isso é preciso, em primeiro lugar, recriar as práticas de desconstrução do populismo conspiratório, especialmente quando essas almejam ter algum impacto fora dos recintos acadêmicos. Como repete há tempo Wu Ming, o coletivo de escritores italiano autor, entro outros, dos romances $Q, 54$, Altai, é necessário que o debunking preserve o mesmo encanto que elas produzem em seus destinatários ${ }^{1}$. Um pouco como fazem os ilusionistas que, ao revelar os truques por trás de suas mágicas, continuam maravilhando e envolvendo emocionalmente seu público.

No entanto, não é possível limitar-se a descontruir, ainda que magicamente, as fantasias conspiratórias que imperam, hoje, mundo afora. Paralelamente, é preciso ignorá-las, sair de suas fronteiras, contar outras histórias. Se não quisermos que elas continuem circulando e tendo visibilidade, devemos deslocar o campo discursivo da disputa política. O que implica, antes de tudo, deixar de falar delas. Pois falar delas, ainda que seja para criticá-las, ajuda a fixá-las na cabeça das pessoas. Como já alertava há tempo o linguista norte-americano George Lakoff, quando digo a alguém "não pense no elefante", a primeira coisa em que a pessoa vai pensar é o elefante². Por isso é preciso fazer das negações, afirmações, transformar os "nãos" em "sins". Imaginar outros mundos. Recriar os que já existem. Reposicionar-se. Reinventar o espaço do debate público ocupando-o com novas narrativas que eludam o adversário, suas pautas e suas provocações.

Antes de começarmos, alguns esclarecimentos necessários e desnecessários. Chamo aqui de "populismo-conspiratório" a conexão íntima e profunda entre os discursos populistas e conspiracionais que povoam o mundo contemporâneo. Ambos caminham, hoje, lado a lado. O populismo divide a sociedade em dois

$1 \mathrm{Wu}$ Ming 1, Q di complotto. QAnon e dintorni. Come le fantasie di complotto difendono il sistema, Roma, Edizioni Alegre, 2020.

2 G. Lakoff, Don't think of an elephant. Know your values and frame the debate, White River Junction, Chelsea Green Publishing, 2004. 
grupos contrapostos : o "povo" e as "elites". Da mesma maneira age o conspiracionismo, segundo o qual existem dois grupos de pessoas : os "conspiradores" (notadamente, as elites) e as "vítimas da conspiração" (notadamente, o povo). Os líderes populistas hodiernos, aliás, têm feito um uso maciço de narrativas conspiratórias para contar ao eleitorado de seus respectivos países "como" e "porque" as elites "corruptas", "moralmente depravadas" e "globalistas" são contra o "povo" e os "cidadãos de bem". Por meio do conspiracionismo, eles têm se consolidado, assim, como figuras "anti-sistema", homens "autênticos" que encarnam à "vontade do povo", construindo um espelhamento recíproco entre eles e as "pessoas comuns". Como todo mundo, os líderes populistas conspiratórios também são - ou melhor, se dizem - vítimas do establishment, dos poderes ocultos, das facções que governam, secretamente, o mundo. A consequência destas narrativas foi a difusão, no seio da opinião pública, de suspeitas sobre o funcionamento do régime democrático, instituições públicas e privadas, políticos tradicionais e autoridades científicas ${ }^{3}$. Uma praxe antiga, mas que, hoje, com a explosão da pandemia de Covid-19, tornou-se ainda mais difusa.

Nas primeiras duas décadas do século XXI, essa postura político-ideológica tem sido adotada principalmente por movimentos, líderes e partidos do campo da "ultradireita" (far right), para usarmos a definição de Cus Mudde ${ }^{4}$. Conforme aponta o autor, o campo da ultradireita engloba movimentos, líderes, partidos, ideologias e pautas da "extrema direita" e da "direita radical", bem como, sempre segundo sua terminologia, subculturas como a alt right norte-americana. $\mathrm{O}$ termo "extrema direita" designa posições que rejeitam explicita e inteiramente a democracia liberal, como no caso do nazismo alemão, do fascismo italiano e das ditaduras militares sudamericanas. A direita radical aparenta aceitar a essência da democracia (ou seja, o voto), mas se coloca abertamente contra alguns pilares da democracia liberal, como, por exemplo, os direitos das minorias, a separação entre poderes, o papel das instituições judiciárias. A alt right, surgida nos Estados Unidos como um fenômeno prevalentemente online, compreende "um conjunto de ideologias de ultradireita, grupos e indivíduos cuja crença central é que a 'identidade branca' está sob ataque por forças multiculturais que se servem do politicamente correto e da justiça social para ameaçar os brancos e sua civilização"s. Enquanto forma e experiência política prevalentemente digital, a alt right diz respeito também a uma questão de "estilo", pois sua identidade é associada às práticas discursivas das redes sociais, como a trolagem, o meme, a provocação, o ultraje, o escárnio, a paranoia. Paranoia, aliás, que configura um dos pilares do pensamento conspiracionista ${ }^{6}$.

3 M. Butter, The nature of conspiracy theory, Cambridge, Polity Press, 2020.

4 C. Mudde, The far right today, Cambridge, Polity Press, 2019.

5 De acordo com a definição do Southern Law Poverty Center : https://www.splcenter.org/fighting-hate/ extremist-files/ideology/alt-right.

6 R. J Hofstadter. “The paraonoid style in American politics”, Harper's Magazine, 77-86, November 1964 ; U. Eco. I limiti dell'interpretazione, Milano, Bompiani, 1990 ; Y. Fechine, "Passions et présence dans le populisme numérique brésilien”, Actes Sémiotiques, 123, 2020. 
Como sempre, as coisas se misturam entre si. Há traços de extrema direita na direita radical e vice-versa. Os temas e as estratégias discursivas da alt-right perpassam constantemente os dois campos. Trump e o trumpismo, Bolsonaro e o bolsonarismo, Orbán e orbanismo, Salvini e o salvinismo, bem como narrativas conspiratórias como QAnon, A grande substituição e o Globalismo - aos quais me apoiarei para elaborar minhas reflexões -, são, por exemplo, fenômenos que apresentam traços de cada uma das "direitas" acima descritas. Por isso prefiro utilizar, neste texto, o termo, mais compreensivo, de "ultradireita".

Passando ao desnecessário, do qual reivindico, no entanto, toda a importância, quero dizer que a estrutura e o temário deste artigo se inspiram àqueles de Da Imperfeição, última obra de Algirdas Julien Greimas, semioticista lituano radicado na França, falecido em $1992^{7}$. Publicado em 1987, o livro consta de duas partes : a primeira, intitulada Fraturas, explora os acidentes estéticos que quebram a rotina do dia a dia, proporcionando frêmitos de maravilha nos sujeitos que os vivem. Tais eventos, no entanto, são efêmeros. Logo depois, a vida retoma o seu curso habitual, caracterizado, muitas vezes, pela usura e perda de sentido dos hábitos cotidianos. Daí o termo "fraturas", que capta e traduz a fugacidade do momento sublime e extático propiciado pelo advento do inesperado. A segunda, intitulada Escapatórias, interroga-se sobre como tornar tais experiências mais douradoras. Sobre como fazer para reinventar cotidianamente o cotidiano, de modo que possamos aprender, quando preciso, a fugir das tentativas de programação, dessemantização e domínio de nossas existências ${ }^{8}$.

Vislumbra-se aqui a possibilidade de repensarmos os modos e os espaços da crítica semiótica do social, bem como sua função pedagógica, terapêutica e política, no sentido mais amplo do termo. "Ressemantizar a vida trocando 'os signos por gestos”, nos incitava a fazer Greimas em Da imperfeição $o^{9}$. É hora de levarmos essas palavras mais a sério.

Foi tendo isso em mente que formulei os títulos das seções que compõem este ensaio, atribuindo-lhes diferentes estatutos gramaticais. Enquanto aqueles da primeira parte (destruens) são todos substantivos - desmontes, encantos, ratiosuprematismo -, os da segunda (construens) são verbos : recriar, sensibilizar, inventar. A intenção é ressaltar tanto a urgência de transformar nossas análises em ações, quanto a abertura e a incompletude que estes atos têm que preservar. Recriar é um predicado em devir. Não há, nem há de haver, nele, nada de acabado ou previamente definido.

Mais uma razão para esta escolha : usei verbos porque não são acabadas as ideias que apresento. Pelo contrário, são caminhos a serem feitos, desbravados, desviados, ramificados. Juntos. Porque se há algo que a semiótica sempre nos ensinou é que toda identidade, seja aquela de uma palavra, de uma ideia, de uma pessoa ou de um grupo de pessoas em carne e osso, define-se exclusivamente

7 A.J. Greimas, De l’imperfection, Périguex, Fanlac, 1987 ; tr. port. Da imperfeição, São Paulo, Hacker, 2002.

8 Sobre essa interpretação contructivista do livro (por oposição à leitura mais comum, de índole "romântico"), cf. E. Landowski, "De l'Imperfection : un livre, deux lectures”, Actes Sémiotiques, 121, 2018.

9 De l'Imperfection, op. cit., pp. 83-90. 
a partir das relações que estes entretêm com seus pares e ímpares, isto é, com aqueles aos quais se parecem e dos quais diferem. Antes das relações que tecemos não somos nada. Sem tecer relações - inclusive com quem não pensa como nós - não vamos para lado nenhum.

\section{Pars destruens - Desmontes}

\subsection{Encantos}

O sucesso dos atuais populismos de ultradireita só pode ser entendido se levarmos em consideração um aspecto muitas vezes esquecido por seus analistas : a dimensão mágica do engajamento individual e coletivo que eles proporcionam ${ }^{10}$. $\mathrm{O}$ mesmo vale para as narrativas conspiratórias às quais os líderes populistas aludem frequentemente em suas falas : QAnon, segundo a qual uma cabala de pedófilos satanistas, da qual fariam parte, entre outros, Hillary Clinton, Barack Obama, George Soros, Tom Hanks, Hollywood de modo geral, Celine Dion e Marina Abramovič, estaria decidindo secretamente os destinos do mundo ; $A$ grande substituição, cuja tese é a de que poderes fortes e ocultos estariam implementando a substituição de europeus e norte americanos brancos por parte de povos oriundos da África e do Médio Oriente; as teorias antivacinas, seja aquelas contra a Covid-19, seja outras ; as teorias sobre a "Vírus Chinês" e a "Plandemia", que defendem que a pandemia do novo coronavírus eclodida em Wuhan no fim de 2019 tenha sido planejada pelo governo chinês e/ou outros entes poderosos não identificados. $\mathrm{E}$ a lista poderia continuar.

O populismo conspiratório de ultradireita do século XXI seduz menos pelo viés argumentativo e mais pelo viés emotivo-passional ${ }^{11}$. Pode-se dizer que ele "encanta". Encanta de maneiras diversas, e sob múltiplas perspectivas, chamando em causa diferentes aspectos da experiência humana e da vida em sociedade. Antes de tudo, ele encanta porque produz, naqueles que se engajam em suas tramas, o que Umberto Eco chamava, ao refletir sobre o comportamento dos adeptos do conspiracionismo, o "excesso de maravilha"12. Toda narrativa conspiratória, diz Eco, funda-se na suposta existência de um segredo. Um segredo que irá proporcionar, a quem conseguir desvendá-lo, fascínio e prazer. Os seguidores de QAnon que descobriram que havia um projeto de domínio global traçado por uma seita de satanistas pedófilos, e que Trump havia sido eleito para combatê-la, foram tomados por um "excesso de maravilha", no qual se tornaram rapidamente viciados. Nos meses e nos anos seguintes, toda vez que encontravam novos "indícios" e "provas" que pareciam confirmar sua cren-

10 Uma exceção é a pesquisa de Giovanna Parmigiani. G. Parmigiani, "Magic and Politics: Conspirituality and COVID-19", Journal of the American Academy of Religion 89(2): 506-529, 2021, https://doi.org/10.1093/ jaarel/lfab053.

11 L. Bianchi, Complotti. Da QAnon alla pandemia. Cronache dal mondo capovolto, Roma, Minimum Fax, 2021. P. Demuru, "Conspiracy theory, messianic populism and everyday social media use in Brazil : a glocal semiotic perspective”, Glocalism, Journal of Culture, Politics and innovation, 3, 2020.

12 U. Eco, I limiti dell'interpretazione, op. cit., p. 87. 
ça, a maravilha aumentava. A cada nota que "Q", o usuário anônimo de 4chan cujo primeiro post na rede deu início a QAnon, soltava sobre a "tempestade" (the storm) que Trump estaria preparando para varrer os inimigos dos EUA, desencadeava-se uma acalorada busca ao "indício", a um "sinal" que, nas falas do ex-presidente, teria confirmado a teoria. Dito de outro modo, ainda com as palavras de Eco, quem pensa e age com base em uma mentalidade conspiracionista tende a "superinterpretar" o que se apresenta diante de seus olhos ${ }^{13}$. Para que tudo, de uma forma ou outra, se encaixe em sua história. Para que tudo, de uma forma ou outra, a confirme.

Cito um exemplo emblemático : o papel que o número 17 tem na narrativa de QAnon sobre o Trump "salvador da pátria". Em um dado momento, os qanons, como são chamados os seguidores de QAnon, perceberam que a "Q" era a decima-sétima letra do alfabeto. A partir desta "maravilhosa" descoberta, iniciaram a reparar que, coincidentemente, havia uma presença "redundante" do número 17 nos discursos e nos tweets de Trump ${ }^{14}$. O mesmo vale pelas teorias sobre a "Plandemia", que traçavam uma correspondência entre o "fato" - logo desmentido - de Wuhan ter sido a primeira cidade no mundo inteiramente coberta pelo $5 G$, e a emergência do novo coronavírus em seu mercado do peixe. "Nada é como parece. Nada acontece por acaso. Tudo está conectado”. São esse os três pilares que definem o conspiracionsimo e as "teorias" que eles produzem ${ }^{15}$.

Vale ressaltar que, para que o encanto e a maravilha continuem vivos, o jogo da descoberta não pode parar. Por isso os segredos nos quais se funda o conspiracionismo são sempre segredos vazios. Porque se o segredo for revelado por inteiro, o jogo acaba. Por isso, mesmo quando as predições catastróficas de quem anuncia o fim do mundo não se realizam, o discurso conspiratório continua vivo. Porque o segredo vazio que o sustenta é preenchido com novos ingredientes narrativos que reanimam a história.

Semioticamente, pode-se então concluir que as narrativas conspiratórias promovidas hoje pela ultradireita populista são discursos "hermético-hermenêuticos" que, para serem percebidos como "verdadeiros", têm que parecerem "secretos" ${ }^{16}$. Secretos com uma alma dúplice e paradoxal, pois se, de um lado, eles têm que ser continuamente descobertos de modo a alimentar "o excesso de maravilha" que a própria busca pela "verdade" promove, do outro não podem ser revelados "por inteiro". Toda narrativa conspiratória tem que alimentar a dúvida, levando seus seguidores a encontrarem, ligando os pontos, a "verdade". Não por acaso, Bolsonaro e seus filhos exortam continuamente seu público a "duvidar" e "tirar suas conclusões" : para implantar a suspeita sobre as mano-

13 U. Eco, ibid., e id., Interpretazione e sovrainterpretazione, Milano, Bompiani, 2002.

14 https://www.forbes.com/sites/jackbrewster/2021/01/20/we-all-got-played-qanon-followers-implodeafter-big-moment-never-comes/?sh=545369033a06.

15 M. Butter, The nature of conspiracy theories, op. cit.

16 A.J. Greimas, “Le contract de véridiction”, Du Sens II, Paris, Seuil, 1983. (Tr. port., Sobre o sentido II, São Paulo, EDUSP-Nanquim, 2014). 
bras ocultas das elites e alimentar o jogo, gratificante e encantador, da caça e da descoberta dos "fatos reais" atrás das "aparências"

São essas as razões pelas quais teorias da conspiração como QAnon foram definidas, por alguns, como um "jogo" e, em particular como um Alternate Reality Games (ARG, Jogo de Realidade Alternativa), ou um Live Action Role Playing (LARP, Jogo de Intepretação ao Vivo). Os primeiros misturam a experiência online e aquela da realidade do dia a dia. São jogos cujo principal objetivo é desvelar mistérios através de indícios que os jogadores encontram na vida real. Ou seja, algo muito próximo à busca de provas, indícios, conexões e correspondências acima descritas.

Os segundos são jogos de representação e interpretação de papeis, ou, dito mais simples e diretamente, "jogos de fazer de conta jogados por adultos" ${ }^{18}$. O desenvolvimento do LARP não segue um roteiro preestabelecido e não possui um final fechado. Pelo contrário, seu bom êxito depende da capacidade dos jogadores de se "ajustarem" entre si e trilharem caminhos inusitados, que possam levar a finais inesperados ${ }^{19}$. Um pouco como aconteceu, para voltarmos ao nosso caso de estudo, com a invasão do Capitólio de Washington do dia 6 de janeiro de 2021 por parte dos seguidores de QAnon e outros grupos da ultradireita norte-americana, todos devidamente mascarados. Pensemos, a este propósito, em Jacob Chansley, mais conhecido como Jake Angeli, o "Xamã de QAnon”. Lembram de seu corpo tatuado com símbolos oriundos da mitologia nórdica, o chapéu com corna e a cara pintada com as cores da bandeira estadunidense ? Eis um exemplo emblemático do porquê QAnon pode ser considerado, sim, um LARP. Ou melhor, uma mistura de um ARG com um LARP, já que, nela, a experiência online e no mundo real se alternam sem fim. Um jogo que Chansley e todos aqueles que invadiram o Congresso dos EUA parecem ter levado excessivamente à sério.

É com base nessas considerações e analogias que Wu Ming 1 propôs mudar, em seu livro $Q$ di complotto. QAnon e dintorni. Come le fantasie di complotto difendono il sistema ("Q de complô. QAnon e além. Como as fantasias de conspiração defendem o sistema"), a expressão "teoria da conspiração" com "fantasia de conspiração". O termo teoria, pois, é ainda carregado de logicismo e idealismo filosófico, e, justamente por isso, não consegue captar a dimensão "imaginativa", "mágica" e "fabulosa" do conspiracionismo contemporâneo. Daqui a esco-

17 Como nos seguintes tweets : "Bolsonaro e Haddad cotados na Lava-Jato. Tirem suas conclusões!" (https://twitter.com/jairbolsonaro/status/1054888224219381763) ; "O FORO DE SP está mais ativo do que nunca : Assista e tire suas conclusões" (https://twitter.com/jairbolsonaro/status/1054888224219381763) ; "A esquerda diz pregar a democracia e os direitos humanos... Tire suas conclusões mais uma vez" (https://twitter.com/search?q=\%22suas\%20conclus\%C3\%B5es\%22\%20(from\%3Ajairbolsonaro)\&src=typ ed_query).

18 Agradeço a Tadeu Rodrigues Iuama, aluno do curso de doutorado em Comunicação da Universidade Paulista, por esta definição e remeto aqui à sua pesquisa sobre o LARP. Veja-se, em particular, T.R. Iuama, "Priori Incantatem : uma discussão sobre a colonização no Larp blockbuster", InTexto, 49, 2020, pp. 209-304. "Liminaridade Lúdica : um olhar para o Larp a partir da ludoterapia", Souza EAD Revista Acadêmica Digital, 26, 2020, pp. 79-91.

19 Sobre o conceito de "ajustamento" e o “inesperado”, veja-se E. Landowski, Les interactions risquées, Limoges, Pulim, 2005 ; tr. port., Interações arriscadas, São Paulo, Estação das Letras e Cores, 2014. 
lha, mais adequada, do vocábulo "fantasia", que passarei, daqui para frente, a $\operatorname{adotar}^{20}$.

Em nenhuma instância, no entanto, estamos diante de fantasias individuais. As fantasias de conspiração são obras coletivas, que só tem sentido se forem vivenciadas enquanto tais. Nas fantasias de conspiração, o que encanta não é a mera descoberta de indícios e provas que a tornam "real", mas o fato de que se trará de uma experiência compartilhada. Como diria Landowski, o encanto proporcionado pelo populismo conspiratório deriva do contato e do contágio sensível que se constrói entre os membros de sua comunidade de adeptos ${ }^{21}$. Where we go one we go all (aonde vai um vamos todos), é um dos slogans de QAnon, que representa bem a importância, para seus seguidores, de estarem e agirem juntos.

Os caçadores de fantasias de conspiração constroem, portanto, em torno delas, suas identidades individuais e coletivas. Trata-se de um ponto central, que, infelizmente, os experts do debunking não entendem. Não entendem que ao "desmontar" as fantasias de conspiração não estão lidando apenas com "dados", "fatos", "evidencias", "notícias". Estão lidando com pessoas. Pessoas complexas, com histórias diversas. Pessoas que têm paixões, sentimentos, afetos. Pessoas que se encantam e querem - como é seu direito - se encantar.

Como defende ainda Wu Ming 1, as fantasias de conspiração são uma panaceia contra a frustração, o desgosto e a raiva em relação ao mundo assim como ele é. O que é preciso entender é que elas se erguem a partir de "núcleos de verdade" que expõem a crueza do mundo em que vivemos : um mundo realmente desigual, governado com base em interesses econômicos e militares, onde existe, sim, o tráfico de pessoas e crianças, no qual atores de Hollywood participam de cultos envolvidos em uma aura de segredos (Tom Cruise em Scientology, por exemplo), em que as grandes industriais farmacêuticas nem sempre se preocupam com a saúde de quem compra seus remédios, para usarmos um eufemismo ${ }^{22}$.

E não apenas isso. As fantasias de conspiração respondem também à exigência de encanto e maravilha, "de perspectivas através das quais observar o mundo de modo diverso e se sentir diferentes”" ${ }^{23}$. É, portanto, na articulação entre o excesso de maravilha proporcionado pelo jogo coletivo de descoberta compartilhada dos segredos do mundo e a emoção de pertencer a uma comunidade de eleitos que conseguiram ter acesso à "verdade" que reside o sucesso do atual populismo conspiratório. Se, para o analista que os olha "de fora", tais movimentos parecem "irracionais", "absurdos", "fanáticos", para quem os vive "de dentro" a experiência é aquela de uma emancipação social "coletiva"

20 Wu ming 1. Q di complotto, op. cit., p. 119.

21 Sobre a relação entre populismo, contágio e alastramento, E. Landowski, "Populisme et esthésie", Actes Sémiotiques, 121, 2018 ; id., "Dimensions sémiotiques du populisme”, Actes Sémiotiques, 123, 2020 ; id., "Crítica semiótica do populismo", Galáxia, 44, 2020 ; F. Sedda e P. Demuru, "Da cosa si riconosce il populismo", Actes Sémiotiques, 121, 2018.

22 Pense-se, a este propósito, em como a indústria farmacêutica contribuiu, através da venda barata e desregulada de remédios à base de opiáceos, à emergência de uma verdadeira epidemia de toxicodependência nos Estados Unidos dos anos 90. Cf. F. Costa, Questa è l’America, Milano, Mondadori, 2020.

23 Wu ming 1, Q di complotto, op. cit., p. 223. 
e "encantadora". Se não entendermos isso, qualquer desmonte, mesmo o mais logicamente elaborado e argumentativamente coeso, continuará sendo ineficaz.

Por fim, há uma última dimensão responsável pelos encantos do populismo conspiratório que é preciso considerar : a sua raiz religiosa e espiritual. Pense-se, a este propósito, no papel do discurso evangélico-pentecostal, em QAnon, bem como de outros discursos e práticas espirituais : new age, yoga, astrologia, coaching, terapias alternativas, curas quânticas, com óleos essenciais, ervas e cristais. Um fenômeno que ganhou o nome de "conspiritualismo", termo com o qual se pretende evidenciar a mistura íntima entre conspiracionismo e espiritualidade ${ }^{24}$.

O mesmo pode-se dizer do bolsonarismo, cuja narrativa é repleta de elementos oriundos do discurso evangélico : escatologia, isto é, profecias sobre o fim dos tempos, misticismo e messianismo. O próprio Bolsonaro, cujo segundo nome é Messias, promoveu implícita e explicitamente essa fábula. Na Páscoa de 2020 (12 de abril), ele associou a tentativa de assassinato que sofreu à ressurreição de Cristo. Durante uma conferência com líderes religiosos brasileiros ele afirmou : "Eu queria falar uma coisa, já que hoje se fala em ressurreição. Eu não morri, mas estive perto da morte (...). Outro milagre aconteceu. O perfil para chegar à presidência não era meu, nada tinha para chegar, sequer tinha partido até março de 2018”25.

\subsection{Ratiosuprematismo}

A estratégia mais utilizada para combater o populismo conspiratório do século XXI tem sido, até agora, o assim chamado debunking. De acordo com o Oxford Dictionary, fazer debunking de algo significa mostrar "porque uma ideia ou uma crença são falsas e porque não é tão boa quanto eles acham que é" ${ }^{26}$. Normalmente, isso costuma ser feito por meio da apresentação de dados objetivos e argumentos lógico-racionais, por meio dos quais pretende-se confutar notícias falsas, crenças pseudocientíficas, narrativas conspiratórias e/ou qualquer discurso não fundado em evidências devida e cientificamente comprovadas.

Um exemplo clássico de debunking é o trabalho desenvolvido desde os anos de 1970 pelo Committee for the Scientific Investigation of Claims of the Paranormal (Comitê para a Investigação Científica de Alegações do Paranormal), que tem como objetivo o desmascaramento das pseudociências. Em tempos mais recentes, o termo foi sendo associado à prática de checagem jornalística e, em particular, ao expediente das assim chamadas agências de fact-checking, cuja rotina se resume a desmontar, passo a passo, as peças desinformativas que circulam no submundo

24 C. Ward e D. Voas, “The emergence of conspirituality”, Journal of contemporary religion, 26, 2011 ; E. Asprem e A. Dyrendal, "Conspirituality reconsidered: How surprising and how new is the confluence of spirituality and conspiracy theory ?”, Journal of Contemporary Religion, 30, 3. Sobre o tema sugiro também o podcast "Conspirituality" : https://www.instagram.com/conspiritualitypod/. G. Parmigiani, "Magic and Politics: Conspirituality and COVID-19", op. cit.

25 https://www.youtube.com/watch?v=yoULwuldiHw.

26 https://www.oxfordlearnersdictionaries.com/definition/english/debunk. 
das redes sociais. Trata-se de uma verdadeira operação de desconstrução lógico-argumentativa de natureza quase jurídica : os fact checkers apresentam provas e contraprovas que desmascaram porque mensagens de texto, áudio, fotos e vídeos que recebemos em nossos celulares são falsos, exagerados, distorcidos, e assim por diante, para usarmos algumas das etiquetas utilizadas pelas próprias agências para rotular a desinformação contemporânea. Quando conversamos com alguém que defende que Trump foi eleito para derrubar a seita de pedófilos satanistas que domina secretamente o planeta, que o Sars-Cov-2 foi criado em laboratório ou que as vacinas contra a Covid-19 são mais um golpe da Big Pharma trazendo dados, evidências, experimentos científicos, falas de Prêmios Nobel da Medicina e da Física que mostram porque e quão ele está errado estamos fazendo debunking. A análise semiótica pode também ser considerada uma prática de debunking. Quando identificamos e expomos as engrenagens discursivas que regem um discurso mentiroso é exatamente isso que fazemos : mostrar como e porque um dado enunciado pode se passar por "verdadeiro".

Ora, mostrar como muitas das histórias que circulam internet afora não são verdadeiras e "tão boas como muitos pensam que são", para retomarmos a definição do Oxford Dictionary, é sem dúvida importante. É importante que existam as agências de checagem, os comités de combate às pseudociências e uma semiótica crítica que desconstrói e exibe publicamente as estratégias do "parecer verdadeiro". Eu mesmo, enquanto semioticista, trabalhei e sigo trabalhando com este fim, e por isso as palavras que seguem têm um certo tom de autocrítica. Pois é, o problema é que o debunking que temos feito até agora não funciona, ao menos não completamente. Nem no plano das interações microssociais, isto é, da conversa face a face entre duas pessoas ou pequenos grupos de indivíduos, nem nas esferas macrossociais onde se disputa o enquadramento do debate público. Isso por uma razão muito simples, que tem a ver com o que vimos, antes, a respeito da dimensão mágica e contagiosa das fantasias conspiratórias e do populismo digital : um discurso baseado apenas em estratégias cognitivas e argumentações lógico-jurídico-racionais nada pode contra um discurso fantástico e maravilhoso, que cativa, encanta, envolve e contagia. Dificilmente crenças mágicas fincadas na epiderme tremula do corpo social são abatidas com a força da razão, se ainda é o caso, neste caso, de falarmos em força da razão.

Como alerta Wu Ming 1, a questão é que o debunking é, em certa medida, uma "narração tóxica", baseada em um regime e uma postura comportamental que o autor chama de "Ratiosuprematismo". Nas palavras de Wu Ming, o ratiosuprematismo configura, de um lado,

a fidúcia excessiva na lógica strictu sensu, na validade de suas asserções, na justeza de seus conteúdos e, por outro lado, a ingenuidade em relação à natureza sugestiva, sedutora e mitopoética da linguagem (...). O ratiosuprematismo enxerga apenas uma antítese entre lógico e ilógico, um embate entre o raciocínio correto e o raciocínio falacioso, uma guerra entre a Ciência e a ignorância. ${ }^{27}$

27 Wu Ming 1, Q di complotto, op. cit., p. 214. 
Primeira consequência do ratiosuprematismo é, de acordo com Wu Ming 1, a "síndrome do furador de bexiga" :

O debunker imagina-se com a Durindana em mão na Batalha de Roncesvales, apunhalando inimigos atrás de inimigos, quando na verdade está apenas furando bexigas com um alfinete, como um valentão em uma festa de aniversário, tornando-se detestável aos olhos das pessoas que, em teoria, deveria convencer. ${ }^{28}$

O debunking ratiosuprematista é uma prática discursiva autocentrada e autorreferencial, que aponta para um lado e acerta em outro : em vez de alcançar quem de fato precisaria alcançar, o seu discurso acaba atingido àqueles que já acreditam nele ${ }^{29}$.

A história contada pelo debunker apresenta um "olhar totalizante" e "anti-dialógico" : diz que as coisas estão "assim" e "assado", que a realidade é "x", "y" ou "z". Com o debunker não se discute : sua abordagem é "objetiva", "imparcial" e não pode ser rebatida, pois ele é a voz da Ciência e da Razão. Atitude, esta, incapaz de enxergar os "núcleos de verdade" presentes nos discursos populistas e conspiratórios, inclusive os mais autoritários. Núcleos de verdade que contam que vivemos em um mundo desigual onde existem, sim, opressores e oprimidos. Desta forma, o debunker reafirma "uma concepção aristocrática da ciência e, de modo mais geral, do lume da razão. O frame é aquele da elite guerreira que defende a civilização contra a barbárie”30. Um pouco como fez, ao longo dos últimos anos, o médico italiano Roberto Burioni em suas brigas no Facebook e no Twitter contra os membros do movimento antivacina, chamando-os de "burros", "atrofiados" e outros epítetos não muito edificantes.

Resumindo, o debunker ratiosuprematista que insiste em desmontar as crenças fantásticas com seus argumentos lógico-científicos e suas evidências factuais é percebido como "um chato". Um "estraga-festa" elitista e arrogante que acha que sabe e pode mais que todo mundo. Um "mala", um tipo sério e triste, que, além de ser extremamente presunçoso, não consegue se divertir. Alguém incapaz de enxergar os encantos do transe coletivo e se deixar contagiar por eles.

A fim de evitarmos equívocos, cabe ressaltar que a chatice do debunker ratiosuprematista diverge de modo radical daquela do troll da Internet, papel que líderes populistas de direita e extrema direita como Trump, Bolsonaro, Salvini, Boris Johnson costumam interpretar com desenvoltura. Ambos têm seu jeito peculiar de "estraga-festas". Onde o debunker é altivo, o troll é singelo. Onde o debunker é refinado, o troll é grosseiro. Onde o debunker é cabeça, o troll é corpo. Onde o debunker é seriedade, o troll é diversão. Onde o debunker é academia, o troll é rua. Onde o debunker é elite, o troll é povo ${ }^{31}$.

28 Ibid, p. 215.

29 W. Phillips, "How journalist should not cover an online conspiracy theory", The Guardian, 6 de agosto de 2018.

30 Wu Ming 1, Q di complotto, op. cit., p. 215.

31 Para uma abordagem semiótica do troll e da trolagem veja-se M. Leone, "Il linguaggio del trolling. Ingredienti semiotici, cause socioculturali ed effetti pragmatici”, Rivista Italiana di Filosofia del Lingua- 
Se não tomarmos consciência das falácias do debunking ratiosuprematista, a batalha contra os encantos dos populismos autoritários e conspiratórios estará perdida. Bem entendido, isso não significa que devemos deixar de checar notícias, verificar histórias, debater fantasias conspiratórias com nossos parentes, amigos, conhecidos. Significa lidarmos com o fato de que é preciso fazê-lo de maneira diferente. Se quiser ser minimente eficaz, a crítica há de trilhar novos caminhos. E isso vale também para a crítica semiótica.

Em seu livro How to talk with a Science Denier (Como falar com um negacionista cientifico), o filosofo da ciência e pedagogo Lee McIntyre repercorre o debate, desenvolvido ao longo da última década, sobre as melhores estratégias para convencer alguém a mudar de ideia ${ }^{32}$. McIntyre cita estudos publicados entre 2017 e 2020 que confutam o célebre artigo de Brendan Nyhan e Jason Reifler, "When correction fails : the persistence of political misperceptions", no qual os autores argumentam que contrabater com dados e evidências crenças falsas histórica e socialmente sedimentadas, tinha um "efeito tiro pela culatra" (backfire effect) : não apenas as pessoas não mudavam de opinião, mas saiam da conversa ainda mais convencidas ${ }^{33}$. Conforme aponta McIntyre, esta conclusão parece ser demasiadamente radical. Sim, as pessoas resistem em mudar suas ideias com base nos fatos, especialmente quando isso fere sua identidade, autoestima e seu pertencimento social. No entanto, a mudança de opinião é possível, mesmo quando a renitência é máxima. E aqui McIntyre, apoiando-se em tais pesquisas, chega a uma conclusão interessante, que nos chama diretamente em causa como semioticistas : não se muda a opinião de alguém apenas através do que se diz, mas também, e sobretudo, do como se diz. Ou seja, a luta contra a desinformação não é somente uma questão de conteúdo, mas também, e quiçá principalmente, de expressão. Refletir sobre este "como" implica uma passagem rumo a outros horizontes, nos quais a crítica semiótica há de se tornar construtiva.

ggio, 2020 ; P. Demuru, F. Pimenta Rodrigues de Oliveira e E. Cuevas-Calderón, "Regímenes de corporeidad y producción de sentido en el discurso visual de Bolsonaro : exploraciones sociosemióticas", Comunicación y Sociedad, 2021 (https://doi.org/10.32870/cys.v2021.7949). Sobre a lógica da provo-cação no populismo digital, veja-se, ainda, F. Sedda, "Salvini, o della provocazione", Doppiozero, 03 set. 2018. Disponível em: https://bityli.com/kVBqGW e F. Sedda e P. Demuru, La rivoluzione del linguaggio social-ista: umori, rumori, sparate e provocazioni/The revolution of social-ist language: moods, noises, shots, provocations. Rivista Italiana di Filosofia del Linguaggio, 13(2), 2019. Disponível em: https://bityli.com/tMB0T2. Acesso em 20 nov. 2021.

$32 \mathrm{~L}$. McIntyre, How to talk to a science denier: conversations with flat earthers, climate deniers, and others who defy reason, Cambridge (Mass.), MIT Press, 2020

33 B. Nyhan e J. Reifler, "When Corrections Fail : The Persistence of Political Misperceptions", Political Behavior (preprint), 2010, https://www.dartmouth.edu/ nyhan/nyhan-reifler.pdf; P. Schmid e C. Betsch, "Effective Strategies for Rebutting Science Denialism in Public Discussions", Nature Human Behaviour, June 24, 2019 (https://www.nature.com/articles/s41562-019-0632-4) ; D. Kwon, "How to Debate a Science Denier”, Scientific American, June 25, 2019 (https://www.scientificamerican.com/article/how-to-debatea-science-denier/) ; L. Hazard Owen, "Yes, It's Worth Arguing with Science Deniers, and here Are Some Techniques You Can Use”, Nieman Lab, June 28, 2019 (https://www.niemanlab.org/2019/06/yes-its-wortharguing-with-science-deniers-and-here-are-some-techniques-you-can-use/) ; C. O'Grady, “Two Tactics Effectively Limit the Spread of Science Denialism”, Ars Technica, June 27, 2019, (https://arstechnica.com/ science/2019/06/debunking-science-denialism-does-work-but-not-perfectly/). 


\section{Pars construens - Recriar}

\subsection{Sensibilizar}

Para enfrentarmos o populismo autoritário e suas fantasias conspiratórias é preciso, então, mudar de registro semiótico. Trata-se de reinventar as linguagens, as práticas e os discursos usados para combatê-los, bem como os afetos que os permeiam. Reinventar, também, a própria crítica semiótica, a qual há de se tornar mais "viva" do que nunca. Ora, essas operações de recriação e revitalização passam, em primeiro lugar, por uma operação de sensibilização. Ou melhor, por três operações de sensibilização.

1. A primeira, que muitos colegas defendem e praticam, é a sensibilização via alfabetização mediática ${ }^{34}$. O verbo sensibilizar tem, nesse contexto, uma acepção mais ampla, relativa, como se costuma dizer, à sensibilização da opinião pública em relação a um problema específico, neste caso os riscos a autoritarismo político e da desinformação a ele atrelada. Diante da explosão das redes sociais e das plataformas online que configuram, hoje, uma das principais esferas da sociabilidade humana, é necessário desenvolver um trabalho de educação, que ensine às pessoas a lerem e interpretar criticamente os conteúdos que circulam nas novas mídias, bem como as formas através das quais são materialmente construídos. É uma tarefa fundamental, especialmente entre os adolescentes, os quais, não por acaso, são entre os mais atraídos pelos discursos da alt right e das extremas direitas mundiais ${ }^{35}$. Não teria espaço, nem é minha intenção, debater e explorar aqui, em detalhe, esta diretriz pedagógica. Limito-me a dizer que isso não pode ser feito com base em práticas e atitudes ratiosuprematistas. Há de haver, no universo da literacia mediática, uma dimensão lúdica, capaz de divertir as pessoas e livrar o aprendizado do fardo do racionalismo e do tédio.

É este o caminho trilhado, entre outros, por Sander van der Linden e Jon Roozenbeek, professores da Universidade de Cambridge, os quais no âmbito de suas pesquisas sobre as estratégias e os métodos de combate à desinformação a respeito da mudança climática, produziram, junto à sua equipe, dois videogames cujo escopo é neutralizar a má informação antes de sua difusão. No primeiro, Bad News (2018), o jogador cumpre o papel de um verdadeiro profissional da desinformação, o qual, para dar visibilidade a si próprio e suas crenças nas redes sociais deve construir e divulgar uma série de notícias falsas e teorias da conspiração. No segundo, Go viral (2020), encomendado pela OMS, retoma a mesma estrutura narrativa do primeiro, focando, desta vez, sobre a desinformação relativa às vacinas contra a Covid-19. A estas operações deu-se o nome de prebunking, justamente porque, contrariamente ao debunking, procuram desmontar preventivamente as peças desinformativas. No entanto, elas podem ter

34 É o que defende, entre outros, a semioticista Diana Luz Pessoa de Barros. Cf. D.L.P. de Barros, "Algumas reflexões sobre o papel dos estudos linguísticos e discursivos no ensino-aprendizagem na escola", Estudos Semióticos, 15, 2, 2019.

35 N.S. Love, "Back to the Future : Trendy Fascism, the Trump Effect, and the Alt-Right", New Political Science, 39, 2. 
um efeito colateral, contribuindo a fazer circular as mesmas ideias e palavras de ordem que se propõem a erradicar.

2. A segunda operação de sensibilização diz respeito às práticas de debunking. É o que propõe Wu Ming 1 a partir de sua crítica aos adeptos do desmonte ratiosuprematista. Para superar esta narração "tóxica" e "elitista", o autor defende a necessidade de refundar o debunking sobre bases não mais exclusivamente lógico-racionais, mas sensíveis e afetivas. Nesta perspectiva, o desvelamento das artimanhas utilizadas pelos ilusionistas do populismo conspiratório é construído a partir de um envolvimento perceptivo e emocional dos destinatários. A descoberta da verdade depende, neste caso, da substituição do encanto proporcionado pela narrativa desinformacional por um outro encanto, o qual, por sua vez, vem a fundar a emergência de um novo saber.

Trata-se de algo próximo ao que fazem os mágicos que desvelam seus truques ou aqueles de charlatães que se passam por bruxos e deuses curandeiros. Como Houdini, grande inimigo do espiritismo, que no começo do século XX desmascarava falsos médiuns imitando suas práticas ilusionastes. Como o Mago Silvan, que na Itália dos anos 1970 replicou os mesmos truques utilizados pelos curadores filipinos celebres na época. Como os mágicos norte-americanos Penn e Teller. Como Mister M, o mágico mascarado, que teve um grande sucesso na televisão brasileira durante a década de 1990. Em todos estes casos, quando o artifício é revelado, a maravilha que ele provoca no público não desaparece. É simplesmente deslocada : não nos maravilhamos mais pela mágica em si, mas por "como" ela é construída. Nesse caso, o sensível é posto à serviço de uma emancipação inteligível, cognitiva. De certo modo, é como se o encanto causado pela descoberta dos mecanismos atrás do truque nos ajudasse a tomar consciência do que está por trás dele, proporcionando-nos um ganho (e um gozo) dúplice. É assim que o debunking deveria funcionar. Pois nenhum transe se vence apenas com a razão. Para combater feitiços é preciso, muitas vezes, de outros feitiços.

Quem fez algo neste sentido foram os próprios Wu Ming e outros coletivos italianos, os quais, entre 1994 e 2000, sob o pseudônimo de Luther Blisset Project (LBP), emplacaram uma série de "pegadinhas" na mídia italiana a fim de sensibilizar (nas duas acepções do termo antes descritas) a opinião pública sobre os riscos sociais do jornalismo sensacionalista. Uma das mais bem sucedidas refere-se à intervenção realizada por Blisset na cobertura sobre uma suposta seita de pedófilos que teria abusado sexualmente de crianças em rituais satânicos. Interceptando estas narrativas, Blisset havia inventado e feito agir, durante meses, nas regiões do Lazio e da Emilia Romagna, uma falsa rede de satanistas devotados a estupros rituais e, paralelamente, um grupo de católicos-fascistas que os caçavam. As façanhas fictícias de ambos os grupos foram muitas vezes noticiadas como reais por jornais e telejornais nacionais.

No entanto, esta era apenas a primeira parte do jogo. O segundo momento, mais importante que o anterior, era o desvelamento da pegadinha. No que tange a este aspecto, cabe ressaltar que Blisset não se limitava a reivindicar suas ações 
e escancarar o fato de que os eventos cobertos pela mídia italiana eram falsos. Além disso, o coletivo revelava os truques que havia utilizado para enganar os jornalistas. Expunha e tornava públicas suas táticas, explicando quais automatismos culturais e distorções do ecossistema da informação haviam explorado para que a "brincadeira" desse certo. Come resume Wu Ming 1 em seu livro, a explicação da pegadinha nestes era mais importante da própria pegadinha ${ }^{36}$. Uma operação de "guerrilha midiática" que, às vezes, surtia efeitos concretos. Graças à serie de pegadinhas sobre a suposta rede de pedófilos satanistas, Luther Blisset contribuiu à absolvição de um pequeno grupo de jovens de Bolonha acusados de fazer parte de uma seita, conhecida como I bambini di Satana (As crianças de Satanás), que teria abusado de menores em seus rituais. Os rapazes passaram por volta de 400 dias em um cárcere de Bolonha por causa de uma ordem de prisão preventiva, sustentada em grande medida na cobertura sensacionalista dos jornais regionais e nacionais, que haviam descrito os rapazes como seres abomináveis devotadas a práticas desprezíveis. Discursos e práticas que a operação de Blisset havia ludicamente desmascarado. Após o término da prisão preventiva, os réus foram absolvidos em todos os graus do processo, recebendo, por fim, em 2004, uma indenização por parte do Estado pelos dias que passaram encarcerados.

Foi também por causa desta história que alguns críticos e analistas políticos chegaram a afirmar que QAnon pudesse ser obra de Wu Ming. Para essa hipótese contribuía o fato de que Wu Ming, ainda sob o pseudônimo de Luther Blisset, havia publicado, em 1999, o romance histórico "Q". No livro, "Q" era um agente secreto do cardeal Giovanni Pietro Carafa, que agia como infiltrado nos movimentos anabatistas da primeira metade do século XI. Identidade oculta que o personagem compartilha com o "Q" de QAnon, suposto membro do governo Trump que avisava a comunidade de 4 chan e 8 chan sobre os planos do ex-Presidente dos Estados Unidos para exterminar a cabala de pedófilos que controlavam o "estado profundo".

Em $Q$ di complotto e outros textos anteriormente publicados em jornais e revistas, Wu Ming 1 e os outros membros do coletivo de escritores desmentem essas teorias, negando qualquer envolvimento com QAnon, mas admitindo a possibilidade que a teoria da conspiração possa ter sido uma pegadinha de algum coletivo de esquerda (a leftist prank) que escapou das mãos de seus criadores tornando-se algo monstruosos. O que alerta também sobre os riscos de pegadinhas à la Luther Blisset na era das mídias sociais, onde, diferentemente da época televisiva, o alcance e o destino de qualquer história é muito mais difícil de prever e controlar.

Voltando à questão da necessidade de construir um debunking que possua, ao menos em algum grau, uma dimensão mágica e sensível, vale destacar, ainda, o fato de que os próprios Wu Ming têm hoje feito isso através da exploração de um gênero literário chamado "não-ficção criativa" e no que eles definiram como 
"objetos narrativos não-identificados" : obras que oscilam conscientemente entre o romance, o ensaio e a reportagem jornalística, entrelaçando estilos e registros próprios de cada um dos gêneros. Também $Q$ di complotto é um objeto narrativo não-identificado, no qual a desmontagem de QAnon é feita com base nas técnicas de "nãoficção criativa". De modo que o leitor, ao descobrir o que está por trás da teoria, não deixe em nenhum momento de se encantar e maravilhar.

3. Chegamos, enfim, à terceira operação de sensibilização, que concerne às interações face a face com quem defende as teorias e as posturas políticas, sociais, históricas, culturais, econômicas, médicas dos trumpismos, dos bolsonarismos, dos salvinismos, dos orbanismos do século XXI.

Voltemos a Como falar com um negacionista cientifico, de Lee McIntyre e a sua constatação de que a mudança de opinião de quem acredita em fantasias conspiratórias depende essencialmente do "como" se conversa com ele, antes do "que" sobre o qual se conversa. Mas o que seria exatamente este "como" ? Na introdução ao seu livro, McIntyre o resume em quatro palavras : respeito, confiança, calor e engajamento com e pelo outro. Em suma, trata-se de abandonar qualquer atitude ratiosuprematista e procurar tecer, na medida do possível e levando em conta o lugar de fala de cada um, uma relação de igual para igual. É preciso, diria Landowski, ajustar-se ${ }^{37}$. Ir além da crítica lógico-racional. Tecer uma interação fundada em afetos e sensibilidades positivas e não na negação apriorística do outro e suas crenças, ainda que ele defenda o terraplanismo, QAnon ou seja contrário as vacinas. Claro, isso pressupõe que por parte do terraplanista ou do antivax haja uma disposição, ainda que mínima, a uma conversa civil. Caso contrário, o que acabo de dizer não se aplica. Com quem ataca com violência não se discute. Não se cai em suas provocações. Melhor ignorar.

Ora, é preciso esclarecer que, como aponta Landowski, em nenhum momento uma atitude como esta há de se basear num "dever moral de amar o outro"38. Pelo contrário, significa interagir com ele a partir de um princípio de "disponibilidade", mostrando abertura e sensibilidade em relação a seus argumentos e, antes de tudo, à sua pessoa. Do ponto de vista da teoria de Landowski, parece uma posição quase paradoxal. Convencer alguém a rever suas ideias é, pois, uma operação que se inscreve no regime da "manipulação", e não do "ajustamento", onde a guiar a interação é a sensibilidade perceptiva e a capacidade de saber sentir o outro. Entretanto, quando também do lado de um antivacina que votou em Bolsonaro, Trump ou Salvini há uma disposição ao diálogo com quem pensa e votou diferente, esquecer que se age com a intenção de virar ideias e votos pode ser, para os fins daquele que busca fazer o outro mudar de opinião, uma estratégia eficaz. E quando isso acontece, talvez a mudança de opinião possa vir a ser o resultado, um pouco inesperado, do próprio ajustamento com o outro. Um acidente feliz, quem sabe, para ambos os interagentes ${ }^{39}$.

37 E. Landowski, As interações arriscadas, op. cit., pp. 47-60.

38 E. Landowski, “Une grammaire de l'alterité”, Introdução ao Forum do Centro de Pesquisas Sociossemióticas, Ciclo IV : A alteridade do mesmo.

39 As interações..., op. cit., pp. 70-73. 
Do ponto de vista prático, isso significa abandonar a linguagem do ratiosuprematista radical chic que chama o outro de "burro", "idiotia", "estúpido", "louco" ou acharmos que estamos diante de um "coitado" que não soube enxergar como e quão foi manipulado. Como já disse, uma posição como esta, além de ser elitista e classista, não capta e valoriza os "núcleos de verdade" que as fantasias de conspiração usadas pela extrema direita em escala global apresentam. Será então preciso achar novas palavras, tons, registros, outros entornos e contornos comunicacionais capazes de reinventar essa oposição. É um caminho impérvio e que demanda paciência, mas é a via, talvez a única, que nos resta percorrer.

\subsection{Inventar}

Isso tudo, no entanto, não é suficiente. As três operações de sensibilização acima descritas apresentam, todas, um problema : apoiam-se e permanecem exclusivamente no campo discursivo do oponente. A alfabetização mediática contra as fake news, o debunking mágico e a sensibilização do diálogo face a face, embora necessários, inscrevem-se dentro do horizonte narrativo estabelecido pelo outro, contribuindo, às vezes a dar-lhe ainda mais visibilidade. Elas não podem ser, portanto, o único plano de ação contra a desinformação do populismo-conspiratório-autoritário.

Além disso, é necessário deslocar o terreno do confronto discursivo com o adversário e ocupar a esfera do debate público com novas pautas. Dito de maneira simples e direta, é preciso inventar e fazer circular outras histórias. Histórias que não tenham nada a ver com aquelas contadas pelo rival com quem se disputa a ocupação do campo político. Soa banal e talvez um pouco meloso, mas é isso que é preciso fazer : imaginar outros mundos, outras vidas, outras conversas, outras formas de sociabilidade. "A imaginação no poder". Era este um dos slogans mais célebres do maio de 1968. Claro, diante do sucesso eleitoral de figuras como Donald Trump e Jair Bolsonaro, difusores de fantasias conspiratórias sem nenhum elo com a realidade, não se pode dizer que a imaginação não tenha chegado no poder. Ironia do destino, diante da qual, no entanto, não se pode cair no desânimo. Como o feitiço que se combate com outro feitiço, a imaginação dominante se enfrenta com novas imaginações. Aliás, que o se diga : toda disputa política é, no fundo, uma luta entre imaginações.

Quem atua no campo da comunicação política strictu sensu e conhece o trabalho dos spin doctors e das equipes de consultores que preparam um candidato para um debate sabe que este é um ponto central para que ele tenha um bom desempenho diante das câmeras. É preciso sair do frame - isto é, da moldura - narrativa traçada pelo opoente. O linguista George Lakoff escreveu um livro fundamental sobre o tema. O título, Don't think of an elephant (Não pense num elefante), resume bem a tese do linguista : se você disser a alguém não pense nisso ou naquilo, a primeira coisa em que a pessoa vai pensar é exatamente o isso ou aquilo. Um pouco como quando se diz "não" a uma criança. "não pega nisso", "não pega naquilo", "isso não se faz”, e, em vez de ouvir e respeitar a 
voz de seu cuidador ou cuidadora, a criança faz exatamente o contrário. Usar negações construídas desta forma pode ser então, muitas vezes, um tiro pela culatra.

Um caso notório citado por Lakoff é aquele de Richard Nixon, o qual, para se defender das acusações do Watergate, disse, entre outras coisas, "Não sou um trapaceiro" ( am not a crook), reforçando, assim, o vínculo entre "ele", Nixon, e o adjetivo "trapaceiro". O resultado foi que, aos olhos da opinião público norte-americana, ele se tornou mais ainda "trapeceiro". Isso vale também pelas práticas de debunking e fact checking que explicam por que a notícia $x$ o $y$ "não é verdadeira", "não é correta", "não é completa", "é distorcida" e assim por diante. O que circula e o que fica na memória coletiva continua sendo, afinal, as tais das "notícias x e y". Repito : não estou querendo dizer que tais operações não tenham sua importância. Pelo contrário. $\mathrm{O}$ que estou querendo dizer é que, além delas, além do debunking e do prebunking é necessário fazer "exbunking”. É preciso sair do "bunker" do debunking, que nos deixa presos dentro das histórias que queremos extirpar.

Mudemos de assunto, falemos de outras coisas. Não respondamos às provocações dos trolls da internet e da política. O que o provocador quer é exatamente que lhe respondamos a respeito do assunto de sua provocação. Melhor e mais eficaz ignorá-lo, mudar de assunto, falar de outra coisa. Se pensarmos bem, não seria exatamente isso que fazem os populistas contemporâneos ? O que faz Bolsonaro quando uma notícia o atinge ? O que fez, por exemplo, quando a CPI da Covid descobriu indícios de um possível esquema de corrupção na compra de vacina indiana Covaxin, ou quando revelou o fato de que o governo havia recusado por meses mais de 70 milhões de dose da vacina da Pfizer ? Voltou a espalhar ilações e mentiras sobre os riscos de fraude eleitoral e as supostas folhas do voto impresso. Ou seja, mudou de assunto. Falou de outra coisa.

É isso que os bons educadores sugerem hoje aos cuidadores de crianças pequenas. O que fazer se se quer que a criança não faça algo ? Deixe de brincar com algo potencialmente perigoso ? De brigar com a amiga ? Conversar, explicar por que aquilo que está fazendo é arriscado para a sua incolumidade física, por que fere o respeito do outro. E, já que o mero "não" é ineficaz e pedagogicamente pouco interessante, propor outra brincadeira, inventar um novo jogo, imaginar, juntos, uma outra história.

É preciso transformar os "nãos" em "sins". Há exemplos, na história da comunicação política, em que isso foi feito com êxito. É o caso da campanha chilena para o plebiscito nacional do Chile de 1998, que ia decidir sobre a permanência no poder do ditador Augusto Pinochet, contada pelo diretor Pablo Larrain em seu filme, No, de 2012. Uma vitória do "Não" teria implicado a convocação de eleições democráticas para a Presidência e para o Congresso. Do lado do "Sim", havia a ditadura. Do lado do "Não" uma frente ampla de partidos de oposição. O símbolo escolhido para a campanha do "Não" foi um arco-íris, que resumia o acordo e a união entorno da recusa a Pinochet. Para acompanhá-lo, escolheu-se um slogan afirmativo e esperançoso : Chile, la alegria ya viene (Chile, a alegria 
está chegando). O filme publicitário em favor do "Não" que foi transmitido na televisão era repleto de pessoas comuns que dançavam, sorriam, se abraçavam e beijavam enquanto cantavam "Chile la alegria ya viene". Tudo isso fez daquele "não" um "sim" : um "sim" à vida contra a ditadura.

Em seu filme, Larrain mostra umas primeiras versões das propagandas projetadas em favor do "Não". Vídeos em preto e branco que mostravam os horrores da ditadura, tanques na rua, violências, torturas. O problema, como enxerga $o$ protagonista do filme, René Saavedra, publicitário fictício contratado pela campanha do "Não", era exatamente que as peças propostas permaneciam dentro do molde narrativo do inimigo. Não sabemos se é algo que de fato ocorreu ou se foi um gesto de licença poética de Larrain. Mas não é este o ponto. O ponto é que nada disso teria funcionado. Para ganhar o plebiscito, conforme aponta Saavedra no filme, era preciso fazer do "não" um "sim", apagar as suas marcas de negação e transformá-lo em uma afirmação. Era preciso contar uma outra história. Uma história de esperança. O medo não ia ser vencido com outro medo, com um "não" que tivesse sido apenas um "não". O que venceu foi o "não-sim", a negação que se fez afirmação.

Talvez por isso, na eleição de 2018, o "Ele não", que se referia alusivamente embora com toda clareza - ao atual presidente do Brasil, não tenha funcionado como alguns esperavam. Apesar de ter proporcionado uma aglutinação de movimentos diversos, uma forte participação e um sentimento de pertencimento coletivos, o slogan e seu uso insistente fizeram com que a campanha dos opositores ao então candidato de ultradireita ficasse exclusivamente no campo da negação. Em nenhum momento o mote foi acompanhado por um "Ele / Ela sim !" Mesmo no segundo turno, a campanha de Fernando Haddad não soube comunicar de modo claro porque, além do "não" a Bolsonaro, teria sido preciso dizer "sim" a ele. Alías, no Brasil, ao menos desde 2016, quando foi votado o impeachment de Dilma Rousseff, todo o discurso da oposição tem sido quase exclusivamente negativo : "Fora Temer", "Fora Bolsonaro", "não vai ter isso", "não vai ter aquilo". Mas se "não vai ter isso" ou "aquilo", o que é que "vai ter" ?

O problema diz respeito a um debate antigo e ainda muito atual entre quem está engajado na disputa político-comunicacional, especialmente online. Não se deveria escrever ou falar o nome do político $x$ ou $y$ porque é contraproducente, já que, além de serem inomináveis, seu nome continua circulando. No entanto, se o objetivo de não nomear alguém é fazer com que ele saia dos holofotes do debate público, dizer "ele", "B.", “o inominável” funciona só até um certo ponto. Mesmo quando usamos estes termos, estamos ainda falando do político $x$ ou $y$. Ora, se se pretende omitir algo ou alguém é preciso usar as figuras e as técnicas retóricas certas. Pois bem, não se omite algo ou alguém com "perífrases" e "epítetos". Perífrases e epítetos são apenas um outro modo de nomear as coisas e as pessoas. Se omite algo ou alguém utilizando "elipses", isto é, não falando deles. Falando de outras coisas ${ }^{40}$.

40 Cf. J.L. Fiorin, Figuras de retórica, São Paulo, Contexto, 2014. 
Recentemente, Luis Ignácio Lula da Silva, principal adversário de Bolsonaro nas eleições presidenciais de 2022, publicou uma foto em seu perfil de Instagram em que aparece abraçando sua namorada, Rosângela da Silva. Lula veste uma camisa e uma sunga preta, que deixa em evidência a tonicidade dos músculos de suas coxas. O casal sorri, feliz. Atrás dele, sob um fundo cinza, desponta uma lua cheia amarela. A imagem foi muito discutida e deu lugar a uma série de memes que comparavam o corpo sarado de Lula àquele mais fraco de Bolsonaro, bem como de outros que ironizavam a respeito de seus atributos sexuais. Ao lado, a legenda afirma : "Já leu os \#76FatosSobreLula ? Tá no Destaque da bio@lulaoficial. Um resumo sobre a trajetória do menino que saiu do semiárido pernambucano, se tornou duas vezes presidente do Brasil e líder mundial no combate à fome e à desigualdade". E, logo abaixo, "Lula chega aos 76 anos ao lado da namorada Rosângela da Silva, a Janja, e segue sendo a principal liderança brasileira a denunciar os desmandos do (des)governo de Bolsonaro e a afirmar : 'O Brasil tem jeito”'.

Tanto a imagem quanto a legenda são um bom exemplo de deslocamento narrativo eficaz em relação ao discurso de Bolsonaro e às narrativas desanimadoras sobre a pandemia e a crise econômico-social que a acompanhou. A foto é uma promessa de um futuro feliz. De que há sempre, mesmo nos momentos mais difíceis, a possibilidade da alegria. O texto começa contando a história de vida e os sucessos de Lula. Em seguida, descreve o presente do ex-presidente ao lado de Rosangela. Imediatamente depois diz que Lula é a principal liderança contra o (des)governo Bolsonaro. Ou seja, nomeia e cita Bolsonaro, mas com uma alfinetada rápida e direta. Termina, por fim, com uma afirmação e um voto de esperança : "a principal liderança a denunciar os desmandos do (des) governo de Bolsonaro e a afirmar [griffo nosso] : 'O Brasil tem jeito”. Bolsonaro é citado e criticado quase casualmente. Apesar de condená-lo, Lula, ou quem cuida de seu Instagram, não fica perdendo muito tempo no campo discursivo de Bolsonaro. $\mathrm{O}$ destaque é conferido à sua história, não àquela do adversário. $\mathrm{A}$ viagem "diplomática" que Lula fez na Europa em novembro de 2021 vai também nesse sentido. Conversando com outros líderes políticos, discursando no Parlamento Europeu e debatendo com jornalistas como se fosse ele o presidente do Brasil, Lula fez esquecer de Bolsonaro, agindo simplesmente como se ele não existisse.

Bem entendido, sair do frame narrativo do opoente não quer dizer perder de vista contra o "que" e "quem" se luta. Toda identidade, a semiótica nos ensina, se define sempre em oposição a outra identidade. Deixar claro "quem é" e "o que" representa o adversário é também central em toda disputa política. Mas, hoje, no ano de 2021, não pode ser a única estratégia de quem se opõe aos populismos autoritários. $\mathrm{O}$ "contra" não tem que sumir, mas há de deixar espaços aos "paras". A alfinetada dada por Lula a Bolsonaro em seu post no Instagram me parece, nesse sentido, ter acertado o nó da questão. Não esquece do rival, mas lhe reserva, em sua narrativa, o espaço que merece. E tem mais : a imagem publicada por Lula cumpre, alusivamente, ou seja, sem falar diretamente 
do assunto, um verdadeiro "saque narrativo". Rouba um dos temas centrais do discurso do atual presidente, dos quais todos ouviram falar antes mesmo de sua campanha eleitoral : aquele do "homem forte" capaz de pôr ordem no país e mantê-lo na linha com sua "intransigência" e "dureza". Aludindo ao corpo frágil de Bolsonaro, por ele muitas vezes representado como tal, a coxa sarada de Lula mostra ao Brasil que é ele o verdadeiro "homem forte" que a nação precisa. E tudo isso sem tocar diretamente no assunto. Talvez, para a oposição, valha mais a pena pesar em estratégias como essa - irônicas, argutas, astuciosas e fáceis de compreender - do que perder tempo decidindo os epítetos com os quais se referir a Bolsonaro. Parece-me muito mais eficaz. Pessoalmente, lamento o fato de que a disputa presidencial se jogue ainda em torno do tema e das figuras da virilidade masculina. No entanto, como semioticista, devo admitir que, com aquela foto publicada em seu Instagram, Lula marcou um ponto a seu favor.

Por fim, quero lembrar que os caminhos da invenção que estou aqui discutindo não devem concernir apenas os discursos, mas também as práticas políticas. É preciso criar novos modos de discutir, fazer, refazer política. É uma questão importante sobre a qual muitos se detiveram em profundidade. Limito-me, portanto, a relembrar um caso exemplar : o "Teatro Legislativo" do diretor, ator e pedagogo Augusto Boal, implementado durante seu mandato como vereador da Câmara Municipal do Rio de Janeiro no início dos anos 1990. A experiência é descrita no livro homônimo, publicado incialmente em 1996 pela editora Civilização brasileira e republicado em 2020 pela Editora 34, edição da qual vale citar por inteiro a quarta capa :

Teatro Legislativo descreve uma experiência pioneira do que hoje tem sido chamado de "mandato coletivo" : a atuação de Augusto Boal (1931-2009), um dos maiores teatrólogos do mundo, como vereador na Câmara Municipal do Rio de Janeiro no início dos anos 1990. Como ele próprio resumiu, "na minha vida inteira sempre fiz política (embora não partidária) e sempre fiz teatro. Foi isso o que me seduziu na proposta : fazer 'teatro como política', ao invés de simplesmente fazer 'teatro político', como antigamente". Foram quatro anos de "imaginação no poder", utilizando as técnicas que o tornaram famoso para teatralizar os problemas nas próprias comunidades que os viviam e, assim, criar um novo modo de elaborar leis. Desde então, a experiência não teve continuidade nos caminhos e descaminhos escolhidos pela esquerda brasileira e justamente por isso pode ser um elemento fecundo para seus atuais impasses. ${ }^{41}$

O livro havia também sido publicado em 1998 em inglês, por Routledge, com um título ainda mais impactante : Legislative theatre: Using performance to make politics (Teatro legislativo : usando a performance para fazer politica). Diversas foram as leis que a equipe de Boal escreveu e conseguiu aprovar, naqueles anos, a partir desta prática. Leis que resolveram problemas concretos das comunidades cariocas e que, ao mesmo tempo, fizeram com que as pessoas tomassem consciência e se aproximassem da política, tanto daquela em sentido amplo, quanto daquela em sentido estrito, relativa às tomadas de decisão por parte de quem 
governa. Pense globalmente e aja localmente, dizia-se algum tempo atrás. Acho que foi isso que, entre tantas outras coisas, fez Boal com o Teatro Legislativo. Uma crítica semiótica que queira ser mais "viva" do que nunca tem muito a aprender com experiências como essa.

\section{Fins}

Esse texto começou com dois "fins" : um fim desconstrutivo, focado em uma análise semiótica crítica dos encantos e do desmonte ratiosuprematista do populismo conspiratório do século XXI e um fim reconstrutivo, centrado em propostas concretas de sensibilização e reinvenção das práticas discursivas que a ele se opõe. Seu "fim", no entanto, não pode ser um. Para uma reflexão como esta, os "finais" hão de ser plurais e diversos. E eu, sozinho, nem consigo escrevê-los. Nem me cabeira. Isso há de ser obra coletiva.

\section{Bibliografia}

Asprem, Egil e Dyrendal, Asbjørn, "Conspirituality reconsidered : How surprising and how new is the confluence of spirituality and conspiracy theory?", Journal of Contemporary Religion, 30, 3.

Barros, Diana Luz Pessoa de, "Algumas reflexões sobre o papel dos estudos linguísticos e discursivos no ensino-aprendizagem na escola", Estudos Semióticos, 15, 2, 2019.

Bianchi, Leonardo, Complotti. Da QAnon alla pandemia. Cronache dal mondo capovolto, Roma, Minimum Fax, 2021.

Boal, Augusto, Teatro Legislativo, São Paulo, Editora 34, 2020.

Butter, Michael, The nature of conspiracy theory, Cambridge, Polity Press, 2020.

Costa, Francesco, Questa è l'America, Milano, Mondadori, 2020.

Demuru, Paolo, "Conspiracy theory, messianic populism and everyday social media use in Brazil : a glocal semiotic perspective", Glocalism, Journal of Culture, Politics and innovation, 3, 2020.

- com Felippe Pimenta Rodrigues de Oliveira e Elder Cuevas-Calderón, "Regímenes de corporeidad y producción de sentido en el discurso visual de Bolsonaro : exploraciones sociosemióticas", Comunicación y Sociedad, 2021 (https:// doi.org/10.32870/cys.v2021.7949).

Fechine, Yvana, "Passions et présence dans le populisme numérique brésilien", Actes Sémiotiques, 123, 2020.

Fiorin, Jose Luiz, Figuras de retórica, São Paulo, Contexto, 2014.

Eco, Umberto, I limiti dell'interpretazione, Milano, Bompiani, 1990.

- Interpretazione e sovrainterpretazione, Milano, Bompiani, 2002.

Greimas, Algirdas J., "Le contract de véridiction”, Du Sens II, Paris, Seuil, 1983 ;

tr. port. Sobre o sentido II, São Paulo, EDUSP-Nanquim, 2014).

- De l'Imperfection, Périgueux, Fanlac, 1987 ; tr. port. Da imperfeição, São Paulo, Hacker, 2002. 
Hazard Owen, Laura. "Yes, It's Worth Arguing with Science Deniers, and here Are Some Techniques You Can Use”, Nieman Lab, June 28, 2019 (https://www. niemanlab.org/2019/06/yes-its-worth-arguing-with-science-deniers-andhere-are-some-techniques-you-can-use/).

Hofstadter, Richard, "The paraonoid style in American politics”, Harper's Magazine, 77-86, November 1964.

Iuama, Tadeu Rodrigues, "Priori Incantatem : uma discussão sobre a colonização no Larp blockbuster”, InTexto, 49, 2020.

- "Liminaridade Lúdica : um olhar para o Larp a partir da ludoterapia", Souza EAD Revista Acadêmica Digital, 26, 2020.

Kwon, Diana, "How to Debate a Science Denier", Scientific American, June 25, 2019 (https://www.scientificamerican.com/article/how-to-debate-a-sciencedenier/).

Lakoff, George, Don't think of an elephant. Know your values and frame the debate, White River Junction, Chelsea Green Publishing, 2004.

Landowski, Eric, Les interactions risquées, Limoges, Pulim, 2005 ; tr. port., Interações arriscadas, São Paulo, Estação das Letras e Cores, 2014.

- “De l'Imperfection : un livre, deux lectures”, Actes Sémiotiques, 121, 2018.

- "Populisme et esthésie”, Actes Sémiotiques, 121, 2018.

- "Dimensions sémiotiques du populisme”, Actes Sémiotiques, 123, 2020.

- "Crítica semiótica do populismo", Galáxia, 44, 2020.

- "Une grammaire de l'alterité", Introdução ao Forum do Centro de Pesquisas Sociossemióticas, Ciclo IV : A alteridade do mesmo, 2021.

Leone, Massimo, "Il linguaggio del trolling. Ingredienti semiotici, cause socioculturali ed effetti pragmatici”, Rivista Italiana di Filosofia del Linguaggio, 2020.

Love, Nancy S., "Back to the Future : Trendy Fascism, the Trump Effect, and the Alt-Right”, New Political Science, 39, 2.

McIntyre, Lee, How to talk to a science denier : conversations with flat earthers, climate deniers, and others who defy reason, Cambridge (Mass.), MIT Press, 2020.

Mudde, Cus, The far right today, Cambridge, Polity Press, 2019.

Nyhan, Brendan e Jason Reifler, "When Corrections Fail : The Persistence of Political Misperceptions”, Political Behavior (preprint), 2010 (https://www. dartmouth.edu/ nyhan/nyhan-reifler.pdf).

O'Grady, Cathleen, “Two Tactics Effectively Limit the Spread of Science Denialism”, Ars Technica, 27, 2019 (https://arstechnica.com/science/2019/06/ debunking-science-denialism-does-work-but-not-perfectly/).

Parmigiani, Giovanna, "Magic and Politics: Conspirituality and COVID-19", Journal of the Amer-ican Academy of Religion 89(2): 506-529, 2021, https://doi. org/10.1093/jaarel/1fab053

Phillips, Whitney, "How journalist should not cover an online conspiracy theory”, The Guardian, 6 de agosto de 2018.

Schmid, Philipp e Cornelia Betsch, "Effective Strategies for Rebutting Science Denialism in Public Discussions”, Nature Human Behaviour, June 24, 2019 (https://www.nature.com/articles/s41562-019-0632-4). 
Sedda, Franciscu, "Salvini, o della provocazione”, Doppiozero, 03 set. 2018. https:// bityli.com/kVBqGW

Sedda, Franciscu e Paolo Demuru, "Da cosa si riconosce il populismo", Actes Sémiotiques, 121, 2018.

- La rivoluzione del linguaggio social-ista: umori, rumori, sparate e provocazioni / The revolution of social-ist language: moods, noises, shots, provocations. Rivista Italiana di Filosofia del Linguaggio, 13(2), 2019. Disponível em: https://bityli. com/tMB0T2.

Ward, Charlotte e Davida Voas, "The emergence of conspirituality", Journal of contemporary religion, 26, 2011.

Wu Ming $1, Q$ di complotto. QAnon e dintorni. Come le fantasie di complotto difendono il sistema, Roma, Edizioni Alegre, 2020.

Résumé : Neste artigo, analiso criticamente a dimensão mágica dos populismos conspiratórios de ultradireita do século XXI, relativa aos encantos que eles são capazes de proporcionar. Em seguida, abordo as práticas de debunking e fact-cheking, através das quais a desinformação política e as fantasias de conspiração são normalmente combatidas. Mais especificadamente, almejo mostrar porque elas são muitas vezes ineficazes contra a maravilha gerada pelo populismo conspiratório. Por fim, apresento algumas propostas concretas para neutralizar o discurso deste último. Defendo a necessidade de sensibilizar as práticas e os discursos utilizados contra eles, bem como aquela de se desvencilhar dos moldes narrativos por eles traçados.

Mots clefs : conspiration (théories de la), debunking, populisme, sémiotique critique

Auteurs cités : Umberto Eco, Paolo Fabbri, Algirdas J. Grerimas, George Lakoff, Eric Landowski, Lee McIntyre, Wu Ming 1

\section{Plan :}

Introdução

1. Pars destruens - Desmontes

1. Encantos

2. Ratiosuprematismo

2. Pars construens - Recriar

1. Sensibilizar

2. Inventar

Fins 